\title{
Five Principles for MOOC Design: With a Case Study
}

\author{
John R. Drake, Margaret O'Hara, and Elaine Seeman \\ East Carolina University, Greenville, NC, USA
}

\section{drakejo@ecu.edu; oharam@ecu.edu; seemane@ecu.edu}

\begin{abstract}
New web technologies have enabled online education to take on a massive scale, prompting many universities to create massively open online courses (MOOCs) that take advantage of these technologies in a seemingly effortless manner. Designing a MOOC, however, is anything but trivial. It involves developing content, learning activities, and assessments to accommodate both the massiveness and openness of the course. To design an effective MOOC, instructors need to integrate both pedagogical and information systems theory. In this paper, we present a case study of a MOOC grant and a series of decisions made in its development. These decisions, when paired with the theoretical framework, suggest five principles - meaningful, engaging, measurable, accessible, and scalable - may be applicable to future MOOC development projects.
\end{abstract}

Keywords: Online education, theory development, instructional design, MOOC, case study

\section{Introduction}

MOOCs (massive open online courses) have been attracting attention worldwide, enrolling thousands of students in hundreds of courses using various technology platforms. There was a period of increased hype about MOOCs in the trade press, including an article in The Wall Street Journal in which Stanford University president John Hennessy said, "There's a tsunami coming." ("Changing the Economics of Education", 2012). The New York Times even declared 2012 "The Year of the MOOC" (Pappano, 2012). After several years of growing passion about MOOCs, there followed a period of time when a variety of MOOCs appeared. While early courses have been primarily designed for baccalaureate level subjects, the massive, open, and online nature of these courses has also attracted the attention of K-12 educators looking to enhance curricular options for younger students as well as post-graduate programs seeking to enhance advanced studies by attracting the top scholars in the field in one centralized location. Because of newer Internet technologies, the cost of creating these courses has fallen, allowing MOOCs to provide their content for free to any student with Internet access. For cash-strapped schools, such free offerings

Material published as part of this publication, either on-line or in print, is copyrighted by the Informing Science Institute. Permission to make digital or paper copy of part or all of these works for personal or classroom use is granted without fee provided that the copies are not made or distributed for profit or commercial advantage AND that copies 1) bear this notice in full and 2) give the full citation on the first page. It is permissible to abstract these works so long as credit is given. To copy in all other cases or to republish or to post on a server or to redistribute to lists requires specific permission and payment of a fee. Contact Publisher@InformingScience.org to request redistribution permission. can help administrators supplement course offerings not normally available to students or those with insufficient enrollment to justify assigning a teacher.

Student attrition in MOOCs has been high (Clow, 2013), suggesting that the goals of students may not be aligned with MOOC goals. Many innovative techniques and tools to interact with and retain students have been tried, from 
discussion forums, badges, and interactive tools, to self-assessments, peer assessments, and automated grading (Kay, Reimann, Diebold, \& Kummerfeld, 2013). These techniques have met with varying degrees of success, but retention rates remain low and barely reach into the double digits (Adamopoulos, 2013). Undoubtedly, innovation will continue at a rapid pace as educators seek ways to present materials and inspire learning in ever more effective ways. Given the vast and ever changing technological opportunities available for course integration, course designers may find it difficult to judge which technologies to incorporate into MOOCs and the impact that those technologies will have on student learning and retention.

The many challenges of online learning - for students, instructors, and administrators - have been researched and discussed many times (Crawford-Ferre \& Wiest, 2012; Shelton \& Saltsman, 2005). Online, however, is only one word in the MOOC title. Because of the massive scale and open nature of MOOCs, not only are these challenges often magnified, an entirely different set of considerations must be adopted to set up the course for success. The massive nature of the course, for example, ensures that instructor interaction with students will necessarily be limited due to the limitations of time and energy of the instructor. Yet research clearly demonstrates that interaction with the instructor is a critical success factor in online courses (Soong, Chan, Chua, \& Loh, 2001). Because humans are social creatures and social activities can enhance learning, interactions with other students can enhance the motivation to continue participating in the learning environment (Wentzel, 1998).

When collaboration mixes people with varying levels of expertise, experience, and knowledge, learning is enhanced (Bellamy, 1996). Design choices that enhance and encourage collaboration within traditional size classes - whether face-to-face or online - cannot be easily employed on a massive scale. While a small group session may work well with instructor supervision and guidance, such an effort may result in extensive dissatisfaction from the students in a MOOC if the instructor cannot be as participative. To avoid poor design choices, course developers need a set of principles to guide their decision-making in building and managing course content, technologies, processes, organizational structure, and administration on a massive scale. While several studies suggest design principles for information and communication technology in education (Kong \& Song, 2013; Zhang, Hong, Scardamalia, Teo, \& Morley, 2011), little effort has been made to synthesize the principles for MOOC development. Furthermore, research demonstrating the application of those principles to a real MOOC design effort is lacking because of the newness of MOOCs. Yet, we know that design has a significant impact on deep and meaningful learning (Garrison \& Cleveland-Innes, 2005). Given the uniqueness of MOOCs and the less than positive results experienced thus far, establishing a set of design principles is critical for improving student outcomes. Ultimately, if principles can guide MOOC design decisions such that MOOCs improve student understanding, retention, and completion rates, MOOCs can fulfill their promise of free education to large numbers of interested students. This paper attempts to fill this gap.

We begin with a review of MOOC-related literature. Because MOOCs have both a pedagogical and technical aspect, we next explore pedagogical theory and information systems theory. Pedagogical and information system development both offer design principles for their respective fields. Next, we illustrate how those five principles guided decision making in a successful grant proposal in a MOOC on economic development. Finally, we discuss what those five principles mean for future MOOC development projects.

\section{Theoretical Frameworks}

The design of MOOCs has been broadly categorized into a few categories - cMOOCs, tMOOCs, and xMOOCs. The Network-based MOOCs (cMOOC) focus on connecting learners in a community of learning environment. Siemens and Downes are often credited for developing the first 
cMOOC in 2008 (McAuley, Stewart, Siemans, \& Cormier, 2011). Task-based MOOCs (tMOOCs) specified tasks for the learner to complete, with content and community as support. The xMOOC typically indicates a MOOC that is content-based, more commonly offered by a university in partnership with an external firm such as Udacity or edX. As the xMOOC grew in popularity and enrollments, it provided very little of the connectivity among its students that the cMOOC had done.

A topology based on pedagogy spans major learning functionalities, including TransferMOOCs, MadeMOOCs, SynchMOCs, AscynchMOOCs, AdapativeMOOCs, GroupMOOCs, and ConnectivistMOOCs (Rosselle, Caron, \& Heutte, 2014). Conole (2014) argues that MOOCs can be classified by twelve dimensions - open, massive, use of multimedia, degree of communication, degree of collaboration, learning pathway, quality assurance, amount of reflection, certification, formal learning, autonomy, and diversity. While an extensive review of related literature is beyond the scope of this paper, the reader is referred to Liyanagunawardena, Adams, and Williams (2013) for a more robust study of the literature. With the multiplicity of MOOC designs, universal principles that are applicable across all of them would need to address two foundational concepts - conceptual development and information systems.

The theoretical basis for this paper comes from two pedagogical theories on conceptual development and two information systems theories. The first pedagogical theory specifies the structural components in instructional design that enable conceptual learning. The second pedagogical theory specifies the principles for instruction, in both design and delivery. From information systems, the first theory identifies necessary components for development of information systems while the second theory identifies how the technology fits within the broader organizational context.

\section{Pedagogical Theory}

In his classic “Assimilation Learning Theory," David Ausubel (1968) developed a cognitive view of education that emphasized conceptual development in learning. In this theory, learning takes place on a continuum from meaningful, deep understanding of newly presented concepts to shallow, rote memorization of concepts. When concepts are learned in a meaningful manner, they persist in memory for longer periods of time, can be applied to new problems and contexts, enable differentiability of related materials, and improve the capacity to learn unrelated subjects (Novak, 2010). Moreover, concepts learned this way approach the upper levels of learning in Bloom's Taxonomy as they enable analyzing, evaluating, and creating new knowledge (Krathwohl, 2002). When concepts are learned in a rote manner, they persist in memory for shorter periods of time, cannot be applied to new contexts, are not differentiable, and are unhelpful in learning unrelated subjects. This rote learning would correspond more closely to the lower levels of Bloom Taxonomy: remembering, understanding, and applying. Meaningful learning of concepts takes place when four things happen: 1) when concepts are clearly defined, 2) when clear exemplars are provided that tie concepts to reality, 3) when concepts are integrated with existing knowledge, and 4) when students are properly motivated to learn the topic (Novak, 2010).

While the first and second criteria for meaningful learning are relatively straight forward for most instructors, integrating concepts with existing knowledge and motivating students are often more challenging and problematic. Ausubel (1968) stressed the third criteria when he argued that one of the most important factors for developing meaningful course materials is correctly assessing the knowledge of students before they start a lesson. This continues throughout the course, as instructors must continuously assess the learning of new concepts when they build upon prior course concepts. This assessment should allow both the student and the instructor to adjust. Stu- 
dents should be able to re-consume the course content they did not understand and the instructor should adjust the course content that was not well received.

It is important to note that meaningful learning is not synonymous with active learning. Novak argued that the two should be viewed as orthogonal (Novak, 2002). Active learning, while championed as a technique for overcoming boring lectures, can induce rote learning in ways similar to lectures. The temptation to rely on active learning puts the wrong emphasis on the course (Drake, 2012). Active learning excels when it stimulates cognitive engagement with the course topics (Mayer, 2004). While cognitive engagement is critical for learning, many students crave social engagement as well. The interaction with other students helps keep motivation levels high, inducing continuous learning (Wentzel, 1998).

In a more recent theory of Objectivist Education, Jamin Carson (2005) states that three principles of instruction should guide instructional design in order to achieve systematic conceptual development. Those three principles are motivation, integration, and structure.

Motivation is a self-regulatory process for engaging in behavior, ranging in a continuum from external stimulus to internally driven (Ryan \& Deci, 2000). In education, motivation represents the motive or moving power of a student to learn a particular subject. Motivation, whether purely intrinsically driven or extrinsically driven, is necessary before students can learn. The greater the internal perceived locus of control the better students show interest, tackle assignments, and put forth effort. Without that intrinsic motivation, instructors can induce motivation to learn through a variety of techniques, each with differing effectiveness levels.

As in Assimilation Learning Theory, the principle of integration is a process of connecting or relating data (Peikoff, 1985). This suggests two important instructional techniques: first, there should be examples and data in which a student must observe, and second, there needs to be a directed process for connecting the observations together. Why directed? Because it took experts hundreds, if not thousands of years to integrate and induce all of the abstractions that now constitute our body of knowledge. We cannot expect students to do the same in a few classes unless we guide them on the integration process. Part of the job of the instructor is to pick appropriate examples, lead the students through the integration process and then lead them back by applying the concept in new situations.

Structure is the third principle of instruction, stating that course materials should be structured to be delivered at the appropriate time in the appropriate order. Ideas form a hierarchy from simple to more abstract concepts (VanDamme, 2006). Just as a student cannot learn algebra until arithmetic is understood, neither can a student learn organic chemistry until basic chemistry concepts are understood. This hierarchy is present across all disciplines and knowledge areas. Teachers must develop a structure of course content that enables students to develop knowledge in a hierarchically appropriate manner. However, teachers have an added challenge when developing a course structure. They have to determine what concepts students already understand before creating their course structure, because the structure should start with what the students are already familiar. If the course becomes too abstract too quickly, the students will be lost. If it stays too simple for too long, the students will get bored.

\section{Information Systems Theory}

Because MOOCs extensively depend on technology, information systems development theory can provide a foundation for understanding the necessary requirements for successful course development. Typically, four phases - planning, analysis, design, and implementation - comprise systems development methodologies. Planning focuses on how feasible the development will be at solving the problem, answering the question about whether the system should be built. The analysis phase determines what the system must do to meet the need of its users and thus be suc- 
cessful. The design phase focuses on how the system will accomplish those goals. In the implementation phase, the new system is developed and implemented.

The focus of this article is on the design phase of systems development, which assumes that the planning of the new system and the analysis of what the system must do are complete and enable the course objectives. While there are various principles of software and interface design, there are two general foci for the usability of new systems (Galitz, 2002). First the system must be easy to use. Second, it must do so effectively, so that it is usable with minimal levels of human performance. According to the Technology Acceptance Model, these two features - perceived ease of use and perceived usefulness - impact the attitude toward a system (Davis, 1989). This model has been shown to be applicable to learning systems (Liu, Chen, Sun, Wible, \& Kuo, 2010; Ngai, Poon, \& Chan, 2007).

Perceived usefulness can be described as the ability of the new system to help the person achieve a specific outcome. In a work environment, usefulness implies that the system helps accomplish the work faster, makes the job easier, and/or increases the employee's productivity. For a classroom related technology, usefulness primarily impacts two types of users: the students and the instructors. For students, a useful system would help them learn faster, make learning easier, and improve their performance on assessments. For instructors, a useful system would help them develop course materials faster, allow them to interact with larger numbers of students, and require less time in helping students achieve the learning objectives.

Perceived ease of use represents the effort necessary to accomplish the outcomes. A system is easy to use if it is understandable, requires little mental effort, and is not frustrating. For a classroom information system to be easy to use, it must also be understandable to both students and instructors, require little mental effort to use, and not frustrate the users. While the course materials may not be easy to use on purpose, the system on which the materials are located should require little effort to learn and use.

Higher Education can be viewed as a socio-technical system (STS) (Watson, Boudreau, York, \& Greiner, 2008). Every organization can be thought of as having two sub-systems: the social and the technical (See Table 1). The social system comprises people and structure; the technical system comprises technology and task. Attributes of people (such as their attitudes, skills, and values), as well as reward and authority structures, are among the concerns of the social system, while the technology that drives task accomplishment are the concerns of the technical system (O'Hara, Watson, \& Kavan, 1999). To optimize the entire system, STS design seeks to maximize the interaction of the two subsystems and their components. In a course environment, we are concerned with faculty and students, the structure of their interaction and the reward system (grades) for students. The tasks are teaching and learning and the technologies run the gamut from a blackboard to a tablet with everything in between.

\begin{tabular}{|l|l|}
\hline \multicolumn{2}{|c|}{ Table 1: Socio-Technical System within Classrooms } \\
\hline SOCIAL SYSTEM & TECHNICAL SYSTEM \\
\hline Structure (Interaction \& Grades) & Technology (All) \\
\hline People (Faculty \& Students) & Tasks (Teaching \& Learning) \\
\hline
\end{tabular}

When any new technology is introduced into a social system, three levels of change can result automating or alpha changes, informing or beta changes, and transforming or gamma changes (O'Hara et al., 1999). When the main impact of a new technology is primarily with the tasks, it is considered an automating or alpha level change. These new technologies automate existing processes and tasks, but have limited impact on people and their roles within the organization. In- 
forming or beta change occurs when the people interacting with the technology change their roles and their tasks. These types of technologies inform the people in unique ways, enabling decisions and alternative tasks not available prior to the technology. When new technology impacts the social structure, the interaction between individuals radically transforms the social system.

In higher education, the introduction of Learning Management Systems automated many of the activities previously performed by students and their instructors. Assignments, for example, could be submitted electronically and syllabi could be delivered and viewed online as well. Such automation could also be accomplished with other technologies. For example, in large classes, clickers greatly automate checking attendance.

When distance education and its associated technologies became popular, the change not only automated the delivery of instruction, but also changed the relationship between the instructor and students. No longer were students and instructors locked into fixed times for class meetings; no longer were they tied to a specific geographic location; and no longer would they necessarily recognize each other on sight. This indicates a beta level change, as both the task and the individuals involved were affected. Flipping the classroom is another example of this type of change. In effect, the roles of the instructor and the students are reversed.

With the advent of MOOCs, a transformative change can occur. MOOCs do not just automate instruction; they do not just change the roles and relationships of those involved; they provide the technology to change the infrastructure and landscape of higher education. There are four ways that the organizational structure can change by implementing MOOCs.

First, as the "M" in the name indicates, MOOCs often have massive enrollments. These large enrollments transform the relationship between instructor and student so that personalized - or even small group - interaction with the instructor is not likely. An instructor simply doesn't have time to interact with students on a personalized and meaningful manner. In discussion forums, students might be promoted to moderators to help manage the course. This extends beyond just classroom discussions, but also includes how instructors provide feedback to students' work. Many MOOCs introduce peer grading, which allows students (usually more than one) to grade the work of other students. While student team members have been evaluating teammate performance for some time, the instructor is typically involved in issuing a final grade for an assignment. With MOOCs, the peer grading may be the final grade.

Second, as the first "O" in the name indicates, MOOCs are open for enrollment to anyone who wants to take the course. This enables students of varying skill and knowledge levels to take the course. Instead of the usual cohort of students taking a set of classes in lock-step through a program, students in MOOCs often do not know each other and interact primarily on an ad-hoc basis. Heterogeneous students may also have radically different experiences and beliefs with only one shared value, the desire to participate in the same particular MOOC. This fact makes informal discussions around local topics (i.e., sports, local news, etc.) less likely, while simultaneously making some topics problematic if such discussions distract from the learning objectives. This might occur if strong disagreements emerge around topics like politics or religion and derail a discussion topic into flame wars.

Third, student interaction within discussion forums or wikis can add value to the course through the construction of new content. While not all MOOCs follow this strategy, it is possible for MOOCs, if structured appropriately, to develop new content over time, without direct instructor input. Technology mechanisms can enable students to police the forums and wikis themselves by reporting misuse, editing other student input, and voting on content they like.

Finally, indirectly, MOOCs are transforming the organizational structure of higher education. Their arrival on the scene of the traditional campus has caused instructors, administrators, and 
students to re-examine the structure and future of the university. While the future of MOOCs may be questionable, there is little doubt that their appearance and potential to disrupt has awakened many in academe (Baggaley, 2014; Waters, 2014).

MOOCs have the potential to transform education through creative destruction and disruptive innovation. The economic theory of creative disruption was introduced by Joseph Schumpeter (1942) who described a cycle wherein innovations replace and destroy existing technologies with newer and more efficient techniques. From this theory, Clayton Christensen (1997) developed the concept of disruptive innovation, defined as a new innovation that creates a new market but eventually disrupts an existing market with a product or service so much more affordable that people who, previously could not afford the products in the old marketplace, can now buy or use the new products or services. In the "Innovator's Dilemma," Christensen (1997) recommends that innovators seize the opportunity for transformation in situations where potential users cannot access a product or service due to lack of affordability or lack of convenience. In a recent interview, Christensen suggests that the way to understand what customers truly want, and to thus avoid obsolescence, is it to see how people work and live (Euchner, 2011).

While disruptive technologies often begin as less profitable alternatives to existing products or services, they have other features that new customers value. Such innovations might be simpler, more convenient, or cheaper to use. Disruptive technologies are often embraced by a small, sometimes fringe, audience of the least profitable customers. While disruptive technologies may not appear to be useful in the current market, they may address future (or new) customer needs and desires (Christensen, 1997).

In education, we typically acknowledge that classroom learning is more effective than computerbased learning. But as information technologies rapidly improve, the quality of computer-based classes is also rapidly improving. With students, we have seen communication preferences and study habits change as technology has become mobile and ubiquitous. Today, students communicate via text, watch clips and videos on their mobile phones, and often do not read textbooks; when they do read, they tend to read in short segments or chunks. MOOCS offer the convenience and the capacity to utilize videos and the information chunking that students have come to prefer. Additionally, because MOOCS are free, they are affordable to individuals previously unable to access university education. For these reasons, MOOCs and their associated technologies may prove to be a disruptive innovation to the education industry as a whole.

\section{Theory Synthesis}

While synthesizing these pedagogical and information systems theories, five principles were discovered that could guide the design and development of MOOCs such that instructors can achieve better impact with course materials. These five principles - meaningful, engaging, measurable, accessible, and scalable - provide a decision-making framework that is applicable across disciplines. Below we articulate each principle and how it can apply to design decisions.

\section{Meaningful}

While virtually all instructors strive to create meaningful content, it is easy to make mistakes such as presenting too many ideas without integrating them, introducing irrelevant topics, presenting ideas in a confusing order, providing insufficient examples or examples students cannot relate to, or introducing boring material uninspiring to students. In smaller classes, any of these mistakes can be identified through direct dialog with the students. When working on a massive scale, these same mistakes are much more difficult to catch or avoid.

A variety of tools and techniques exists to facilitate meaningful learning in a MOOC, including cognitive and meta-cognitive prompts, short distilled lectures focusing on single topics, study 
guides, concept maps, and self-assessment quizzes. Even discussion boards can induce meaningful learning by encouraging more experienced students to share examples with the less experienced students, thereby helping all the students to integrate the ideas in a more holistic fashion. The primary value in focusing on meaningful learning, however, is that it helps the course designer put the student's learning first and keeps MOOCs with their corresponding capabilities as secondary concerns.

\section{Engaging}

Although it may be tempting to include engaging as a sub-topic of meaningful learning, it deserves special attention when working on a massive scale. Consider that high attrition rates in MOOCs are often considered a norm. It is not uncommon for fewer than $5 \%$ of the total students signed up for a course to finish that course (Daniel, 2012). Thousands of students may enroll, but only hundreds may complete all of the course content. This may not mean that the course was a failure, however, because students may take the course for any number of reasons, and a completion certificate may not be one of them ("MOOCs Impact at Duke University," 2013). However, the fact remains that MOOCs present a challenge in engaging students because of their massive size. Instructors do not have the energy and time to interact with students in the same way they can in smaller classes.

We focus on two general types of engagement: cognitive engagement and social engagement. Cognitive engagement can be accomplished with traditional education techniques, including lectures, but careful attention should be paid to best practices in these techniques in order to elicit the best effect. For example, lecture videos should be kept short (Sugar, Brown, \& Luterbach, 2010). Instructors should also remember that jokes and colloquialisms may be lost on students from different cultures. Cognitive engagement could also be enhanced with immediate feedback on student work through automated grading.

Social engagement addresses the major limitation of traditional computer learning. Students in a classroom often enjoy the interaction with fellow students and with instructions. This is often difficult to duplicate online. In MOOCs, care should be given to facilitate all potential interactions through technologies such as discussion forums and virtual chat rooms, or possibly scheduled regional meet-ups. Furthermore, instructors can enhance engagement with automated email messages and reminders.

\section{Measurable}

Measuring student progress and course material effectiveness is a staple for course development of all types. But in MOOCs, the massive size allows for and calls for vastly more precise evaluation and assessment, unavailable in smaller class sizes. The massive size of MOOCs creates a massive amount of data which, coupled with the technology inherent with MOOCs, allows for more meticulous evaluation of course efficacy. Furthermore, because everything is done online, every action made on the platform can be tracked. With appropriate analysis, two forms of measurement improvements become available - first from the students' perspective as they track their own progress, and second from the instructor's perspective when viewing progress of the students.

Many MOOCs provide progress splash screens that display feedback on course accomplishments, from completion of homework assignments to passing quizzes and exams. With massive sample sizes, statistical analysis such as means and standard deviations become useful benchmarks. In discussion forums, up or down voting threads and comments provides quick measurements of student interest, allowing students to focus more quickly on good and interesting ideas. The mas- 
sive number of samples allows artificial intelligence programs to better evaluate student homework and provides instant feedback.

Given the size of the class, it is easy for instructors to lose touch with the effectiveness of course content. Measurability puts some of that touch back in the hands of instructors so they can adjust content to be more effective. Instructors can see quantifiable evidence regarding which discussion questions gained the most interest. They can view which content items were viewed most often, even being able to see if the same video was viewed more than once. Statistics software can be used to relate success on the exam with various factors in students and their usage of class materials. Furthermore, instructors can continuously monitor and research learning goal outcomes to provide immediate feedback during the course.

\section{Accessible}

Because of the open nature of MOOCs, students of all sorts can join the class. The level of knowledge of students varies dramatically. Students may range from high school students to $\mathrm{Ph} . \mathrm{D}$. students. Some join the course to learn a brand new subject, while others join to brush up on an area with which they are already familiar. Some students join to learn skills for a job; others join for the pure joy of learning something new. While some students may have high bandwidth Internet connections, many still work with low bandwidth connections. Students may prefer various methods of presenting content or suffer from a variety of disabilities. It is impossible to address all the variations, nor is it recommended, but placing an emphasis on accessibility is necessary for satisfying truly massive numbers of students.

There are a number of things that can be done to enhance accessibility. For example, many MOOCs have no pre-requisites. Given the large variety of skill levels and experience of potential students, this may not be entirely warranted. There may be some assumptions on ability to read or write or some base understanding of science in general. To overcome these limitations, scaffolding of materials may help students of differing skill levels maximize their learning (Hogan \& Pressley, 1997). Another option might be to supplement video lectures with audio only or transcripts for low bandwidth consumption.

\section{Scalable}

To achieve massive scale, a course should be designed for thousands of students through the use of automated systems. While this assumption was implicit in much of the discussion above, it warrants its own discussion because of its importance to the concept of MOOCs. Scalable systems have the capability of growing from small to large with only minimal adjustments. This necessarily prohibits certain types of classroom structures and techniques. Classes that depend heavily on classroom discussion may find massive online discussion chaotic and disorderly (McGuire, 2014). Instructors may find it difficult to personally diagnose conceptual misunderstandings and to correct them.

Effective design of MOOCs requires scalability, and such scalability is achievable through automated systems enabled by Internet technologies. To enable scalability, instructors should be limited to three points of contact throughout the course: 1) creating content, 2) managing operations, and 3) assessing student progress. Although teaching assistants can be added as attendance grows, there are limits to the number of teaching assistants that can be effectively utilized. The free nature of MOOCs creates a financial incentive to ensure scalability. 


\section{Illustrative Case Study}

In conducting an illustrative case study, the study questions, unit of analysis, logic linking the data to the propositions, and the criteria for interpreting the findings must be identified during the research design (Yin, 2009). The study question we pursued was "How can pedagogical and information systems principles be used when making decisions among several alternative options when designing a MOOC?" The case study format lends itself to "How" questions because it enables a researcher to follow operational links over time so as to better explain phenomena under question (Yin, 2009). As indicated in the study question, the unit of analysis is a decision with several alternative options made by the course development team. These decisions are all embedded within a single MOOC design, chosen because it was deemed representative of typical MOOC design efforts.

Data was collected from three sources: the MOOC proposal, email archives of the MOOC proposal team members, and two participant observers. Participant observation was deemed necessary for this case because the email archive did not always articulate the reasons behind decisions. In order to better develop the context of the decisions, it was essential to have someone from inside the project to verify if the reasoning used in making decisions adopted the principles in question. The email archive was used to reduce the potential for bias from the participant observers and to fact-check their accounts of events. We also utilized two different participant observers to help triangulate accurate accounts of the group's decisions and reasoning.

\section{The MOOC Grant}

In July of 2013, the University of North Carolina (UNC) System issued a request for proposals (RFP) to develop a MOOC on the theme of emerging economies. As part of the UNC System's strategic priority "to leverage technology to enhance student learning and strengthen academic equality," a key objective of the UNC MOOC RFP was to assess opportunities and limitations of the MOOC format for delivering high quality education with measurable student learning outcomes (UNC General Administration, 2013).

The RFP included three features that distinguish this MOOC from others that had been developed. The developed course would be offered to students throughout the world as well as to matriculated UNC System students who would receive course credit. Additionally, grant applicants were encouraged to develop inter-institutional teams from the UNC System institutions and to involve faculty and experts from around the world in delivery of part of the course. The RFP specifically required that there be no prerequisites for the course, that flexible assignments be structured that could be used by both for-credit and non-credit students, and that the course be designed to appeal to a broad range of students. Also required were research and learning objectives, strategies for promotion, and delivery and assessment plans. SAS Institute would partner with the awardees in developing the learning management system (LMS), video classroom, discussion rooms, and other necessary elements of the MOOC platform.

Three professors at two UNC institutions were awarded the RFP for their proposal, "The Economics of Emerging Markets: Exploring the Transformation of Developing Economies into Developed Nation Status". The proposal incorporates the success factors outlined earlier in the paper:

"The following five goals framed our thinking on specific pedagogic and structural components of the MOOC:

Meaningful - To enable meaningful learning, we will provide content that stimulates understanding of core concepts and their relationship to the world. 
Engaging - We will keep the course engaging to limit attrition by providing feedback for completion and/or inactivity, communities of interest, and public recognition for accomplishments.

Measurable - Both students and instructors will have access to measurable progress on usage of learning objects and technology, as well as success in understanding course concepts.

Accessible - The content and structure of the course is designed to be accessible to matriculated UNC students, non-traditional students, global participants, UNC alumni, and individuals interested in applying to UNC schools.

Scalable - To achieve massive scale, the course is designed for thousands of students through the use of automated systems. Instructors will have three points of contact throughout the course - 1) creating content, 2) managing operations, and 3) assessing the results. None of these three hinder scalability." (Seeman, Drake, \& Maysami, 2013)

In a brief video highlighting a UNC/SAS partnership for developing the MOOC platform, Dr. Tom Ross, president of the UNC System, detailed these five critical objectives (Ross, Goodnight, \& Goodnight, 2014). The proposal specified that course content would be created by the economics professor in the group and organized into modules consisting of reading assignments, brief single topic video lectures, cognitive and meta-cognitive prompts, calendars, study guides, and discussion questions. Further, a self-assessment quiz at the end of each module would verify mastery of the material. Successfully passing a self-assessment quiz would result in a user earning a badge. Badges would display on user profiles, in the Q\&A forum, and in the virtual communities.

The course would offer two discussion mediums. An interactive Q\&A would algorithmically determine popular questions and answers and give those questions prominence in the forums. The algorithm would be based on up/down voting for each discussion post, the number of comments, and the date of the votes and comments. This would keep recent and popular discussions near the top of the discussion boards, while less recent or less popular discussions would receive less prominence. Instructors and guest lecturers would vet popular questions for misunderstandings and add their own comments. To encourage interactivity, using the up/down voting system to rate discussions, top vote getters would receive recognition on the Q\&A forum and in the virtual communities. The second discussion mode would give participants access to virtual communities with web conferencing capabilities. These virtual communities would be assigned algorithmically to maximize commonalities across student demographics, yet diverse enough to spark deep conversations around course material. Communities would be capped at 25 students to foster discussion, collaboration, idea-sharing, and motivation. Study guides would prompt discussion around module content.

Along with the self-assessment quizzes offered to all students, matriculated UNC students would also write short papers throughout the course which would be graded both through grading software (to evaluate writing quality and guard against plagiarism) and through randomly assigned peer assessment. Additionally, for-credit students would take two proctored exams administered on the learning management system and proctored using the UNC Proctoring System.

The proposal laid out plans to conduct ongoing, formative evaluation of the use and usefulness of delivered technologies and learning objects throughout the course. This ongoing evaluation would enable the instructors, in consultation with an instructional designer, to adjust focus and emphasis throughout the semester by conducting ongoing, formative evaluation. The goal of the evaluation is to keep students engaged and promote meaningful learning while sharing those findings with the academic community. 


\section{Case Analysis}

While developing the MOOC proposal, various pedagogical and technological ideas were considered. However, only four exhibited a clear choice among alternatives. Using pattern matching logic (see Yin, 2009), we explored the reasoning behind each of the decisions and matched that reasoning with the above identified principles. We also explored any alternative reasons not identified above. In each of the decisions, one or more of the options was rejected because it failed to satisfy one or more of the principles.

\section{Core text}

In the first decision, three options were considered for establishing the core text of the course. The first two options consisted of using "The Economist," a weekly financial and economic publication, but with two different payment methods - paid by the students or paid by the grant. In the third option, content in the public domain was considered.

While "The Economist" offers discounted student subscriptions, it was felt that even that nominal price might discourage students from taking the course because of their expectations that the course is free. Accessibility would be limited by requiring students to sign up for the magazine in order to take the course. The team considered paying for the subscription from the grant money, but that would not have been scalable. If a large number of students signed up for MOOC, there would not be sufficient grant funds to cover subscriptions to all the students. The team approached "The Economist" in order to offer a fixed sum for all enrolled students, paid for by the grant. This would have enabled the accessibility and scalability of course content. However, "The Economist" preferred not to operate on a fixed sum payment plan. Because this last option was predicated upon "The Economist," the decision was outside the control of the team members.

The alternative text considered was the use of materials in the public domain. Many of these were online articles or government published documents. After consulting with the university librarians, the team decided to adopt a mix of online articles and resources. Table 2 summaries the core text alternatives and how they manifest the five principles.

\begin{tabular}{|l|l|l|l|}
\hline \multicolumn{4}{|c|}{ Table 2. Core text decision } \\
\hline PRINCIPLE & $\begin{array}{c}\text { THE ECONOMIST } \\
\text { - PAID FOR BY } \\
\text { STUDENTS }\end{array}$ & $\begin{array}{c}\text { THE ECONOMIST } \\
\text { - PAID FOR BY } \\
\text { GRANT }\end{array}$ & $\begin{array}{l}\text { PUBLIC DOMAIN } \\
\text { MATERIALS }\end{array}$ \\
\hline Meaningful & High & High & High \\
\hline Engaging & High & High & High \\
\hline Measurable & High & High & High \\
\hline Accessible & Low & High & High \\
\hline Scalable & High & Low & High \\
\hline
\end{tabular}

\section{Student Communication Platform}

The second decision consisted of how best to connect students in the course. The team considered two options: using an existing "Global Classroom" technology platform or using online virtual communities. With the "Global Classroom," live video streams could facilitate synchronous discussions with students at North Carolina universities and students at a university in the emerging economy country being studied. Students not involved in the synchronous discussion would be able to view a recording of the session at their convenience. The alternative was to offer virtu- 
al communities with web conferencing capabilities. The communities would be assigned to all students algorithmically and capped at 25 students to foster a tight knit group for discussion, collaboration, idea-sharing, and motivation (Fay, Garrod, \& Carletta, 2000).

While the "Global Classroom" promised a very engaging experience, the team wondered if the recorded sessions might be problematic for those unable to participate and only view the sessions later. It would have created two tiers of students, those able to participate live and those relegated to watching videos. The team thought the two tier system might decrease engagement for those students relegated to watching and not participating. Given the limitations of the "Global Classroom" technology, it was also not scalable to hundreds or thousands of students. Moreover, it required very high speed Internet connectivity for streaming high quality video both ways in real time. Furthermore, students in the North Carolina universities would have more accessibility than students unable to travel to the classroom. The team discarded the concept for these reasons.

Alternatively, the team considered establishing virtual communities enabled with web conferencing to accomplish the same purpose. Because there are a number of web conferencing tools that utilize free user interfaces, accessibility would be high. Most web conferencing tools allow communication with or without video, diminishing bandwidth as an accessibility factor. By restricting the community size and assigning them algorithmically, scalability would not be a problem. Furthermore, the size limitation would helpfully create a close knit community enabling high engagement. Table 3 summaries the communication technologies considered and how they manifest the principles.

\begin{tabular}{|l|l|l|}
\hline \multicolumn{3}{|c|}{ Table 3. Student communication platform decision } \\
\hline PRINCIPLE & \multicolumn{1}{|c|}{$\begin{array}{c}\text { GLOBAL CLASS- } \\
\text { ROOM }\end{array}$} & $\begin{array}{c}\text { VIRTUAL COMMU- } \\
\text { NITIES }\end{array}$ \\
\hline Meaningful & High & High \\
\hline Engaging & Low & High \\
\hline Measurable & High & High \\
\hline Accessible & Low & High \\
\hline Scalable & Low & High \\
\hline
\end{tabular}

\section{Scope of Coverage}

The third decision entailed the scope of countries to include in the course. Two alternatives were considered. One entailed great breadth, with modules on China and Korea, South Asia (India, Pakistan, and Bangladesh), Malaysia and Singapore, Middle Eastern nations (Iran and Turkey), Latin America nations, and African nations. The other alternative was to go into more depth with just four nations - Singapore, Malaysia, China, and India. The team had planned on using a range of guest lecturers, with expertise in each of the nations, which should have helped maintain a higher level of engagement over all of the different nations.

As the team considered the integration of topics and the comparative analysis that they wanted students to make, they ultimately chose to limit the countries studied to only four to avoid a survey type approach with no strong end product. By going deeper into the history of economic development in just four countries, students would better be able to identify the causes and predict the implications of such development in currently developing nations. The team thought this would result in more meaningful content, allowing in-depth consideration of what specifically helped or hindered the development of these Asian economies. Table 4 summaries the scope of coverage and how they manifest the five principles. 


\begin{tabular}{|l|l|l|}
\hline \multicolumn{3}{|c|}{ Table 4. Scope of coverage decision } \\
\hline PRINCIPLE & \multicolumn{1}{|c|}{$\begin{array}{c}\text { BROAD } \\
\text { COVERAGE }\end{array}$} & $\begin{array}{c}\text { NARROW 4 COUNTRY } \\
\text { COVERAGE }\end{array}$ \\
\hline Meaningful & Low & High \\
\hline Engaging & High & High \\
\hline Measurable & High & High \\
\hline Accessible & High & High \\
\hline Scalable & High & High \\
\hline
\end{tabular}

\section{Class engagement measurement}

In the fourth decision, two different strategies for improving class participation were considered. First, a class participation grade could be awarded based on the amount of participation in the discussion forum. Second, a badge system was proposed that could award badges for accomplishing specific objectives within the discussion forum and elsewhere in the course. Both were considered engaging and meaningful. Both could scale to thousands of students. Both were considered accessible.

However, in order to make discussion board grading scalable for thousands of students, the grade would have to be completely automated. Of particular concern to the team was that quality discussion is notoriously hard to evaluate with automated grading. With automated calculations, clever students could potentially manipulate their responses or collude with other students in order to achieve high participation grades, without meaningfully improving the discussion. The badges, however, focus less on punitive results and more on positive rewards. Although badges are automatically graded as well and could potentially be manipulated, the team believed the focus on positive rewards would lead to more accurate measurements than discussion forums. Table 5 summaries the class engagement mechanism and how they manifest the five principles.

\begin{tabular}{|l|l|l|}
\hline \multicolumn{3}{|c|}{ Table 5. Class engagement measurement decision } \\
\hline PRINCIPLE & $\begin{array}{c}\text { GRADED DISCUSSION } \\
\text { FORUM }\end{array}$ & \multicolumn{1}{c|}{ BADGE SYSTEM } \\
\hline Meaningful & High & High \\
\hline Engaging & High & High \\
\hline Measurable & Low & High \\
\hline Accessible & High & High \\
\hline Scalable & High & High \\
\hline
\end{tabular}

Table 6 maps the decisions against the five principles for MOOC development. Factors limiting criteria are indicated by an L (for Low). 


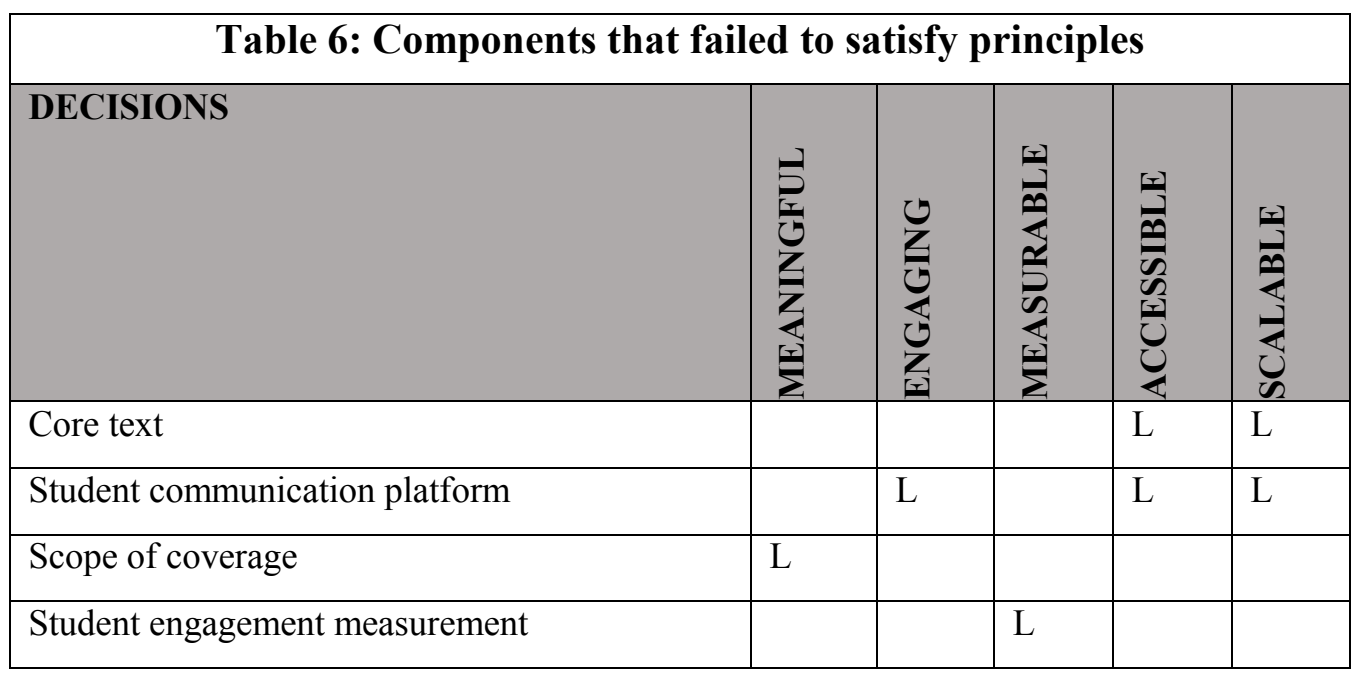

\section{Discussion}

Although the MOOC is still a relatively new concept, it has inspired new approaches to higher education. Simultaneously, online teaching and learning has gained greater legitimacy, with many universities offering new online classes and degrees. Flipped classrooms, problem-based learning, and other technology supported learning approaches are receiving more attention in the trade press as well as serious research efforts in both the education and technology fields. All of these approaches can lead to better, more informed teaching and learning practices, as well as more advanced technologies to support such practices. But for these teaching and learning practices to be a success, they must be based on theories of conceptual development and information systems that enable meaningful learning for all students in the class.

The principles developed in this research came from within a theoretical framework structured using four theories - two each from education and information systems. We believe these theories provided a useful and robust theoretical basis for the research, but it is clear that there are many other theories in both education and information systems and from other fields, such as psychology, communication, and sociology. Future research should extend this theoretical framework, both in breadth of principles and in depth of application. For example, researchers might explore how Media Richness Theory (Daft \& Lengel, 1984), Innovation Theory (Rogers, 2003), or Social Cognitive Theory (Bandura, 2001) could enrich the number or application of these principles.

This research has its limitations. A common concern with case study research is that the results are not generalizable to all instances. We attempted to avoid that limitation by using a MOOC that received funding and was illustrative of common xMOOC efforts. We also used principles that were abstract enough to be useful in most MOOC design efforts. However, future research could explore the extent that $\mathrm{cMOOC}$ and $\mathrm{TMOOC}$ designers have used these principles or found them beneficial to their design efforts.

Future research should also apply these principles to various pedagogical concerns, such as teacher student interaction, student-to-student interaction, learning analytics, group interactions, task completions, quality assurance, etc. As the landscape of higher education continues to evolve and technology continues to advance, research opportunities will surely abound. 


\section{Conclusion}

In this paper, we articulated five principles that can help MOOC instructors design and manage massive classes. These five principles - meaningful, engaging, measurable, accessible, and scalable - were synthesized from conceptual development and information systems theory. We also demonstrate how these five principles were used in selecting components and features of a winning grant proposal for a collaborative, multi-institution MOOC through the UNC System. Decisions on what components and features to include had to pass the requirements for each principle before being adopted. We highlight four decisions where alternative components were considered and rejected because they failed to satisfy all five principles. While assuredly additional principles will be identified and added to this list, these five principles provide a foundation for instructors designing and developing new MOOCs in the future.

\section{Acknowledgements}

Supported by a grant from The University of North Carolina General Administration.

\section{References}

Adamopoulos, P. (2013). What makes a great MOOC? An interdisciplinary analysis of student retention in online courses. Paper presented at the 34th International Conference on Information Systems, Milano, Italy.

Ausubel, D. P. (1968). Educational psychology: A cognitive view. New York, NY: Holt, Rinehart and Winston.

Baggaley, J. (2014). MOOC postscript. Distance Education, 35(1), 126-132.

Bandura, A. (2001). Social cognitive theory: An agentic perspective. Annual Review of Psychology, 52, 126.

Bellamy, R. K. E. (1996). Designing educational technology: Computer-mediated change. In B. A. Nardi (Ed.), Context and consciousness: Activity theory and human-computer interaction (pp. 123-146). Cambridge, MA: MIT Press.

Carson, J. (2005). A philosophical analysis of objectivist education. Unpublished doctoral dissertation, University of Texas at Austin.

Changing the Economics of Education: John Hennessy and Salman Khan on how technology can make the college numbers add up. (2012, June 4). The Wall Street Journal. New York, NY. Retrieved May 19, 2015, from http://www.wsj.com/articles/SB10001424052702303640104577440513369994278

Christensen, C. (1997). The innovator's dilemma. Boston, MA: Harvard Business School Press.

Clow, D. (2013). MOOCs and the funnel of participation. Paper presented at the International Conference on Learning Analytics and Knowledge, New York, NY.

Conole, G. (2014). A new classification schema for MOOCs. The International Journal for Innovation and Quality in Learning, 2(3), 65-77.

Crawford-Ferre, H. G., \& Wiest, L. R. (2012). Effective online instruction in higher education. Quarterly Review of Distance Education, 13(1), 11-14.

Daft, R. L., \& Lengel, R. H. (1984). Information richness: A new approach to managerial and organizational design. Research in Organizational Behavior, 6, 191-233.

Daniel, J. (2012). Making sense of MOOCs: Musings in a maze of myth, paradox and possibility. Journal of Interactive Media in Education, 3.

Davis, F. D. (1989). Perceived usefulness, perceived ease of use and user acceptance of information technology. MIS Quarterly, 13(3), 319-340. 
Drake, J. R. (2012). A critical analysis of active learning and an alternative pedagogical framework for introductory information systems courses. Journal of Information Technology Education: Innovations in Practice, 11, 39-52. Retrieved from http://www.jite.org/documents/Vol11/JITEv11IIPp039052Drake1011.pdf

Euchner, J. (2011). Managing disruption: An interview with Clayton Christensen. Research Technology Management, 54(1), 11-17.

Fay, N., Garrod, S., \& Carletta, J. (2000). Group discussion as interactive dialogue or as serial monologue: The influence of group size. Psychological Science, 11(6), 481-486.

Galitz, W. (2002). The essential guide to user interface design: An introduction to GUI design principles and techniques (2nd ed.). New York City, NY: John Wiley \& Sons, Inc.

Garrison, D. R., \& Cleveland-Innes, M. (2005). Facilitating cognitive presence in online learning: Interaction is not enough. American Journal of Distance Education, 19(3), 133-148.

Hogan, K., \& Pressley, M. (Eds.). (1997). Scaffolding student learning: Instructional approaches and issues. Advances in learning \& teaching. Cambridge, MA: Brookline Books.

Kay, J., Reimann, P., Diebold, E., \& Kummerfeld, B. (2013). MOOCs: So many learners, so much potential. AI and Education, 28(3), 70-77.

Kong, S. C., \& Song, Y. (2013). A principle-based pedagogical design framework for developing constructivist learning in a seamless learning environment: A teacher development model for learning and teaching in digital classrooms. British Journal of Educational Technology, 44(6), 209-212.

Krathwohl, D. R. (2002). A revision of Bloom's taxonomy: An overview. Theory into Practice, 41(4), 212218.

Liu, I.-F., Chen, M. C., Sun, Y. S., Wible, D., \& Kuo, C.-H. (2010). Extending the TAM model to explore the factors that affect intention to use an online learning community. Computers \& Education, 54(2), 600-610.

Liyanagunawardena, T. R., Adams, A. A., \& Williams, S. A. (2013). MOOCs: A systematic study of the published literature 2008-2012. The International Review of Research in Open and Distance Learning, 14(3), 202-227.

Mayer, R. E. (2004). Should there be a three-strikes rule against pure discovery learning? American Psychologist, 59(1), 14-19.

McAuley, A., Stewart, B., Siemans, G., \& Cormier, D. (2011). The MOOC model for digital practice. Retrieved April 3, 2015, from http://www.elearnspace.org/Articles/MOOC_Final.pdf

McGuire, R. (2014). The best MOOC provider: A review of Coursera, Udacity, and Edx. San Francisco, CA. Retrieved April 15, 2015, from http://www.skilledup.com/articles/the-best-mooc-provider-areview-of-coursera-udacity-and-edx

MOOCs Impact at Duke University: An Interview with Peter Lange, Provost. (2013). MOOCs Forum, 1(P), $2-5$.

Ngai, E. W. T., Poon, J. K. L., \& Chan, Y. H. C. (2007). Empirical examination of the adoption of WebCT using TAM. Computers \& Education, 48(2), 250-267.

Novak, J. D. (2002). Meaningful learning: The essential factor for conceptual change in limited or inappropriate propositional hierarchies leading to empowerment of learners. Science Education, 86(4), 548571.

Novak, J. D. (2010). Learning, creating, and using knowledge (2nd ed.). New York, NY: Routledge.

O'Hara, M. T., Watson, R. T., \& Kavan, C. B. (1999). Managing three levels of change. Information Systems Management, 16(3), 63-70.

Pappano, L. (2012, November 4). The year of the MOOC. The New York Times. Retrieved from http://www.nytimes.com 
Peikoff, L. (1985). The philosophy of education. CD Lecture Series. Irvine, CA: The Ayn Rand Institute. Rogers, E. M. (2003). Diffusion of innovations (5th ed.). New York, NY: Free Press.

Ross, T., Goodnight, J., \& Goodnight, A. (2014). UNC and SAS MOOC partnership. YouTube.com: UNC Connect.

Rosselle, M., Caron, P. A., \& Heutte, J. (2014). A typology and dimensions of a description framework for MOOCs. Paper presented at the European MOOCs Stakeholders Summit 2014, Lausanne, France.

Ryan, R. M., \& Deci, E. L. (2000). Intrinsic and extrinsic motivations: Classic definitions and new directions. Contemporary Educational Psychology, 25(1), 54-67.

Schumpter, J. A. (1942). Capitalism, socialism, and democracy. New York, NY: Harper.

Seeman, E., Drake, J. R., \& Maysami, R. (2013). The economics of emerging markets: Exploring the transformation of developing economies into developed nation status. Grant proposal for University of North Carolina General Administration's Emerging Markets MOOC RFP.

Shelton, K., \& Saltsman, G. (Eds.). (2005). An administrator's guide to online education. Information Age Publishing, Inc.

Soong, M. H. B., Chan, H. C., Chua, B. C., \& Loh, K. F. (2001). Critical success factors for on-line course resources. Computers \& Education, 36(2), 101-120.

Sugar, W., Brown, A., \& Luterbach, K. (2010). Examining the anatomy of a screencast: Uncovering common elements and instructional strategies. International Review of Research in Open \& Distance Learning, 11(3), 1-20.

UNC General Administration. (2013). Guidelines for UNC leveraging technology to strengthen academic quality: UNC emerging economies MOOC. Retrieved August 15, 2013, from https://epulsenews.wordpress.com/2013/07/13/rfp-issued-for-emerging-economies-mooc/

VanDamme, L. (2006). The hierarchy of knowledge: The most neglected issue in education. The Objectivist Standard, 1(1).

Waters, J. K. (2014). Breaking the MOOC model. Campus Technology, 27(9), 18-23.

Watson, R. T., Boudreau, M.-C., York, P. T., \& Greiner, M. (2008). Opening the classroom. Journal of Information Systems Education, 19(1), 75-85.

Wentzel, K. (1998). Social relationships and motivation in middle school: The role of parents, teachers, and peers. Journal of Educational Psychology, 90(2), 202-209.

Yin, R. K. (2009). Case study research: Design and methods (4th ed.). Thousand Oaks, CA: SAGE Publications.

Zhang, J., Hong, H.-Y., Scardamalia, M., Teo, C. L., \& Morley, E. (2011). Sustaining knowledge building as a principle-based innovation at an elementary school. Journal of the Learning Sciences, 20(2), 262307. 


\section{Biographies}

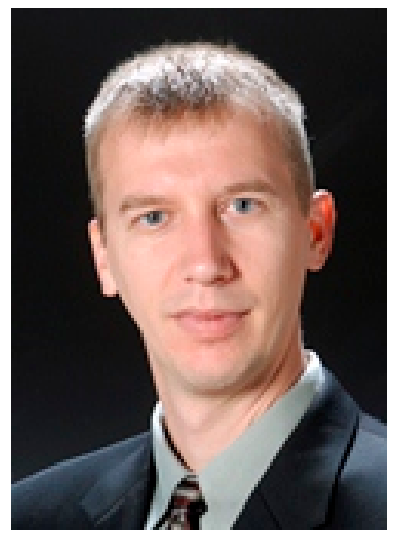

John Drake is an Assistant Professor of Management Information Systems at East Carolina University. He holds a BS in Physics from Southern Illinois University at Edwardsville and a Ph.D. in Management of Information Technology and Innovation from Auburn University. His research has appeared journals such as Journal of Business Ethics, Journal of Information Technology Theory and Application, Journal of Theoretical and Applied Electronic Commerce Research, and the Journal of Information Technology Education. His current research interests focus on developing effective web presence strategies, social media privacy, online education, and business ethics. Prior to academy, John was an IT professional and consultant for 5 years.

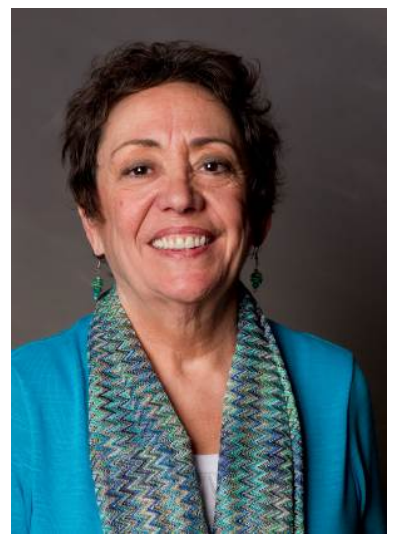

Margaret (Maggie) O'Hara has been teaching Management Information Systems since 1992. She received her Ph.D. from the University of Georgia. At East Carolina University since 1999, she became Assistant Dean for Online Learning in the ECU College of Business in 2005. From 2012-2014, she served as Director of E-Learning for the University of North Carolina system. O'Hara has published research in both MIS and Education journals and consulted internationally on technology-enhanced teaching and learning.

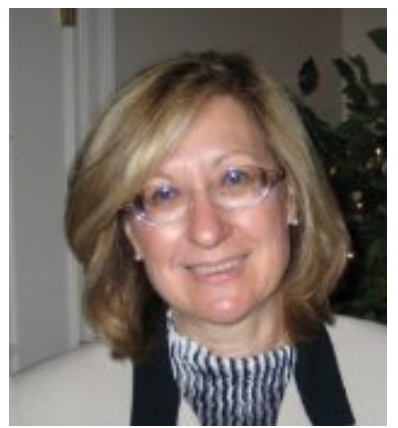

Elaine D. Seeman is an Associate Professor of Management Information Systems at East Carolina University. She received her B.A. from Indiana University of Pennsylvania in 1973, her M.B.A. from East Carolina University in 1997, and her Ph.D. from Indiana State University in 2002. Elaine's major research stream involves the technology implementation, deployment, and related regulatory issues for emergency call services or 911 . This research stream includes more than 10 publications, a $\$ 150,000.00$ contract, and requests to share expertise with the FCC, US Dept. of Transportation, EENA and NENA. 